\title{
Minimum wage effects on employment and working time of Chinese workers_-evidence based on CHNS
}

Wenkai Sun, Xianghong Wang ${ }^{*}$ and Xiaoxi Zhang

* Correspondence: shwang06@ruc.edu.cn

School of Economics, Renmin University of China, ZhongGuanCun Ave \#59, Beijing 100872, China

\begin{abstract}
This paper examines the impact of minimum wage policies on employment, income, and working time of Chinese workers. Using data from China Health and Nutrition Survey, we focus on identifying the effects of minimum wage adjustments using a pre-specified model. We control for lagged minimum wage standard, individual characteristics, provincial population and economic factors, and fixed effects of province and year. We find some evidence of minimum wage impacts on wages and employment for limited groups. Increase of minimum wage has positive effect on wage income only for low-income workers and has negative employment effect only for workers in private and individual enterprises. While minimum wage shortens the average working hours for employed workers, it does not have significant effect on the relative working times for different income groups. These findings may imply some beneficial effects of the minimum wage policies for Chinese workers.

JEL code: J22, J31, J38.

Keywords: Minimum wage, Employment, Income, Working time
\end{abstract}

\section{Introduction and policy background}

Minimum wage policy has been used in many countries as an instrument to regulate the labor market. China started to implement such policy since joining ILO's "Minimum Wage-Fixing Machinery Convention" in 1984. In November of 1993, China issued a formal government executive order that first set the minimum wage regulations. Since then, minimum wage standard was first tested in some developed regions such as Shenzhen and Zhuhai. Some new legislatures served as the earlier framework for minimum wage policies, including "Regulations on Minimum Wages in Enterprises" and "Labor Law of the People's Republic of China". In March of 2004, when the new "Minimum Wage Regulation" was issued, minimum wage started to be formally and widely implemented in China, covering all types of enterprises. Since that year, many provinces set up new minimum wage standards frequently. In 2004 alone, 24 provincial governments raised their minimum wage standards, with an average increase of $20 \%$. In the "Labor Contract Act" of 2008, the addition of minimum wage provision further strengthened the power of minimum wage (MW) policy. After 1 year's pause of 
minimum wage adjustment during the financial crisis of 2008, the second wave of frequent MW changes appeared since 2009.

There are a few features worth noticing about minimum wage policies in China. First, the level of minimum wage is relatively low, about $32 \%$ of the workers' average wages, while the international ratio of minimum wage to average wage is about $40-60 \%$ (Han and Wei 2006). Second, the growth rate of minimum wage is lower than that of average wage, with their relative ratio reduced from 0.44 in 1995 to 0.31 in 2011 (Du and Pan 2009). This statistical trend is shown in the list of provincial minimum wage standards in Appendix A1. The effectiveness of minimum wage policy might be limited if the minimum wage standard are too low compared with the equilibrium market wages. Third, minimum wage standards are set by provincial governments. The minimum level, frequency, and timing of minimum wage adjustments may vary between regions. Therefore, studying the minimum wage effects at the country level is not likely to obtain reliable results.

Minimum wage policies have been long debated among scholars. Some are concerned that minimum wage will distort resource distribution, reduce efficiency, leading to increase of poverty (e.g., Stigler 1946). Others contend that minimum wage may actually increase employment and income (e.g., Card and Krueger, 1994). Opinions about minimum wage policies in China are also divided. Zhang (2004) criticizes the minimum wage policy as a way of price control, reducing China's industrial competitiveness. Tong (2006), however, argues that labor cost only accounts for a small part of firms' production cost in China, so minimum wage will not significantly affect competitiveness of Chinese firms.

Empirical findings from studies of minimum wage effects in China are not all consistent. Wang and Gunderson $(2011,2012)$ study the employment effect of minimum wage using provincial data. They find negative effect of minimum wage on employment in low-growth regions, especially in firms that are not stately owned. Luo (2007); Luo and Cong (2009) find that minimum wage reduces employment of migrant workers and slightly increases wages for all occupations. Xiao and Xiang (2009) study the minimum wage spillover effect using panel data between 1995 and 2006 from six large cities. They find that minimum wage can narrow the wage gap for employees.

To further facilitate the debate about minimum wage policies, this paper investigates minimum wage effects using individual level data from multiple aspects including employment, income, and with some special attention to working time. The existing literature in China seems to have focused much on the direct effects of minimum wage on employment, wage, and firm profit, but rarely on working time of workers except in Jia (2014). Working time can be used by firms as an adjustment instrument to respond to the minimum wage policies (Couch and Wittenburg 2001; Linneman 1982). When hourly minimum wage level is raised, firms can reduce costs through reducing working hours and increasing work intensity. If minimum wage standard is set for a month, firms can dilute hourly pay through increasing monthly working hours. It is worth to investigate whether the minimum wage effect on working time is significant and whether it has spillover effect on working hours of higher income group.

We combine micro data from China Health and Nutrition Survey (CHNS, 2004, 2006, 2009, and 2011), provincial minimum wages, macroeconomic and population statistics to form pooled cross-sectional empirical analysis. Our analyses for minimum wage effect on wages and income distribution are based on the methodological framework used by Neumark (2001); Neumark et al. (2004). In the study of spillover effect on working time, we 
extend the method of Neumark et al. (2004) that is originally used for the study of spillover effect for wages. The channels of wage spillover effect may come from internal substitutions between workers within a firm and changes in workers' reservation wages (Neumark, et al. 2004; Flinn 2006; Wang 2012). The same logic also applies to possible spillover effect on employee's working time. This paper contributes to the existing literature mainly in three aspects. Frist, while existing studies in China mostly depend on macro data or very short panel data sets, our household data observed in 4 years between 2004 and 2011 cover longer time span, contain more detailed information, and contain more frequent provincial minimum wage changes. Second, compared with the simple Difference-in-Difference method traditionally used in minimum wage studies, using method of pooled crosssectional analysis makes it possible to analyze effects of multiple minimum wage changes over time. Third, we fill the gap of minimum wage effect on working time in the existing literature, especially its possible spillover effect.

The rest of the paper is organized as follows: Section 2 describes the data sources and main variables; Section 3 explains the analytical methods; Section 4 and Section 5 report empirical results and robustness check; Section 6 concludes the paper.

\section{Data}

The data sets used in this paper are drawn from three sources. The individual level data for employment, wage and working hour are obtained from CHNS. Provincial minimum wages are compiled by the authors from various policy outlets provided by provincial governments. Macro-economic statistics and population statistics are drawn from China's statistical yearbooks. The three groups of data are described as follows.

\subsection{Individual level data for workers}

CHNS is a household and individual survey jointly conducted by the Carolina Population Center at UNC- Chapel Hill and the Chinese Center for Disease Control and Prevention. Nine surveys have been carried out since the first one in 1989, covering nine representative provinces of China including Liaoning, Shandong and Jiangsu in the east, Heilongjiang, Henan, Hubei and Hunan in the Central region, and Guizhou and Guangxi in the west. The survey contains information on demographic characteristics, employment and work, consumption and expenditure, diet and nutrition, health condition, and leisure time activities. While CHNS has been used mainly for studies of health related topics, it contains rich information that has allowed for studies of labor issues (Chen et al. 2014), children's education (Chyi and Zhou 2014), income inequality (Ward 2014) and many others. Studies on minimum wage issues in China have started to use micro-level data only in recent years because micro-level data are limited and are often not publicly available for research. Some studies of MW impact on wages are found using the Urban Household Survey which was conducted by National Statistics Beauru of China (NSB) (Wu and Perloff 2005; Fang and Lin 2013), and Rural Migrant Workers' Monitoring Survey conducted by NSB (Yang and Gunderson 2013). This study makes use of the information on workers' working time contained in CHNS. As far as we know, few studies have studied MW effect on working time.

To investigate the effects of China's minimum wage policies, we select CHNS data from 4 years, 2004, 2006, 2009 and 2011, covering two waves of minimum wage 
adjustments periods, containing a sample of 15,159 individuals in total. Appendix A2 describes all the variables available for the selected years. Appendix A3 summarizes the demographic characteristics for different income groups. The summaries indicate that the sampled observations are distributed rather evenly across different years, regions, sectors, ages and genders, which is helpful in our analysis for heterogeneity of minimum wage effect among different regions or different groups.

\subsection{Minimum wage data}

The data for provincial minimum wages $(\mathrm{MW})$ are collected from issued regulations and documents on adjustments of minimum wage published at the provincial government websites and news media. These include monthly minimum wage standard, hourly minimum wage standard, and specific implementation time of the new standard. Some provinces have multiple minimum wage levels set for different regions within the province. Based on the method of Neumark (2001), we use the highest level as the minimum wage standard for that province. Appendix A4 shows monthly minimum wages of the selected provinces from 2004 to 2011 . As shown by the trends of the two time periods divided by 2008 and 2009, the later period witnesses a more dramatic increase in adjustment frequency, adjustment magnitude, and a larger gap between Eastern, Central and Western regions compared with the earlier period.

The actual implementation dates of minimum wage adjustments vary between provinces because provincial governments have the discretionary power for implementation decisions. In order to make annual minimum wage standard in 1 year comparable between provinces, we follow the method of Rama (2001) and adjust it by computing the average of the monthly minimum wage weighted by the number of months covered by that MW standard during the 12 months of that year. The coverage-adjusted annual minimum wage standards are listed in Appendix A5 for the sampled provinces from 2004 to 2011. Over the 7 years' period, the minimum wage level in different regions increased by nearly three times. Across regions, the absolute value of the annual minimum wage in the east is noticeably higher than that in the Central and Western regions. The Central region has slightly higher minimum wage level than the Western region.

\subsection{Provincial macro data}

The provincial macro-economic data and population statistics are compiled from national or regional statistical yearbooks, including major indicators such as per capita GDP, agricultural share of economy in the province, and population of labor force. As Appendix A6 shows, from 2004 to 2011, all provinces experienced a rapid growth in per capita GDP, a constant decline in the share of agricultural sector, and a relatively stable working population. The differences in macro-economic indicators among provinces should be controlled for in analyzing minimum wage effects.

\subsection{Main variables}

By compiling the above three sources of data, we forma a panel data set that includes micro household survey and macro socio-economic statistics in nine provinces of China in 2004, 2006, 2009 and 2011. 
We mainly analyze three dependent variables, employment, wage income, and weekly working hour. Working time is reflected both by whether a person is employed or not and by weekly working hours. We define "employment" (employment $=1$ ) as being engaged in a job under the minimum wage system and being at a working age. Specifically, respondents are supposed to be non-students between 16 and 65 years old, employed with a positive wage income. They should not be retirees who are reemployed after retirement. Excluded observations also include farmers, military officers, soldiers and other unspecified occupations; self-employed, household helpers and those with unspecified jobs; workers under the household contract responsibility system and other unspecified sectors. The first column of Appendix A2 shows that the ratio of employed to popolation has been declining at an average annual rate of $42.27 \%$. Male labors outnumber female labors, and rural labor force outnumbers the urban one. The highest proportion of the labor force is the group aged between 30 and 49 , followed by the young adults aged between 16 and 29. In terms of education level, those with a college degree or higher accounts for the highest proportion of employed. In contrast, only $38 \%$ of those with a primary school diploma are employed.

Monthly wage income is our second variable of interest. Within the sampled years, the monthly wage income has experienced an increase, reaching 2109 RMB yuan in 2011. The average wage of a male worker is higher than that of a female, and the wage of urban employees is higher than that of rural employees. Young adults aged between 16 and 29 who have just started their career, and middle-aged people aged between 40 and 59 who have reached the peak of their career receive the highest income. Those with a college degree or higher receive higher wages than others. The average wage income in Eastern and Central regions of China is considerably higher than that in the Western regions. Wage income is also higher for permanent employees than for contract and temporary workers, and higher for state-owned public institutions, research institutions and government agencies than for collective and privately-owned enterprises.

The third dependent variable of our focus is weekly working hours. Considering the whole sample, the average working hour per week is 43.5 , which is higher than the statutory cap of $40 \mathrm{~h}$ ' working time per week. ${ }^{1}$ There is no significant difference between males and females in number of working hours. Yet significant difference is observed between urban and rural areas, with urban employees working shorter hours than rural employees. Working hours tend to reduce with the age of a worker.

The core independent variable in this study is the ratio of the minimum wage (adjusted for coverage time) to the average wage. For the whole sample, the ratio is $32.33 \%$ on average ${ }^{1}$. Contrary to the absolute value of the minimum wage, the relative minimum wage (minimum wage/average wage) has declined, despite a slight recovery in 2011.

In order to investigate possible spillover effect of minimum wage adjustment on different income groups, we divide the workers into seven groups of different income levels according to the ratio of their wage relative to the minimum wage, using $20 \%$ as the division range within each group. These six income groups are: less than $90 \%$ of minimum wage (the minimum-income group), $90-110 \%$ of minimum wage, $110-130 \%, 130-150 \%, 150-$ $170 \%, 170-190 \%$ and more than $190 \%$ of minimum wage. The average proportion of the seven groups in the sample from 2004 to 2011 is illustrated in Appendix A3. The minimum-income group accounts for $13 \%$ of the sample; high-risk group (whose monthly wages are between the old and new minimum wage standards) accounts for $8.49 \%$. 
Among the minimum-income group and high-risk group, there are twice female workers as male workers, and twice rural workers as urban workers. Education level is negatively related to the probability of falling into the low-income groups. Those with an education level of lower than primary school is 12 times more likely to belong to the minimum or high-risk group than those with a college degree or higher. In addition, contract workers, temporary workers and family workers are more likely to receive a lower wage than permanent employees.

\section{Methodology}

\subsection{Overall effect of minimum wage}

In analyzing minimum wage effect on employment, scholars typically use the following time series model (Neumark 2001):

$$
E_{t}=\alpha_{0}+\alpha_{1} M W_{t}+X_{t} \beta+\varepsilon_{t}
$$

where $E_{t}$ is a dummy for employment status; $M W_{t}$ is the minimum wage adjusted for coverage time; $X$ is a set of control variables to control economic cycles and effects of demographic changes; and the subscript $t$ indicates different time periods.

Due to China's large size and uneven socio-economic development across the country, using national data undoubtedly conceals large differences in the minimum wage effects of various regions, which gets in the way of identifying the real impact of minimum wage adjustment. By integrating both micro data and macro data at the provincial level, we adopt the method of pooled cross-section analysis as seen in Neumark (2001); Wang and Gunderson (2011). Specifically, we estimate the following model:

$$
Y_{i, t}=\alpha_{0}+\alpha_{1} M W_{i, t}+\alpha_{2} M W_{i, t-1}+S_{i, t} \beta+\text { Year }_{t} \delta+\text { Province }_{i, t} \lambda+\varepsilon_{i, t}
$$

where $Y_{i, t}$ is the dependent variable; $M W_{i, t}$ is the minimum wage adjusted for coverage time; $M W_{i, t-1}$ is the minimum wage adjusted for coverage time in the prior period; $s_{i, t}$ is a set of variables to control for economic cycles and demographic changes; Year $_{t}$ and Province $_{i}$ are fixed effects for year dummies and provinces.

The dependent variables include whether a person has a job (employment), logarithm of monthly wage (lnwage), and logarithm of weekly working hours (lnhour). For the first dependent variable, we estimate a Logit model adjusted for heterogeneity in variances. For the latter two dependent variables, we use the robust ordinary least squares (OLS) method to estimate for the subsample of workers with a job (employment $=1)$. In all three estimates, we control for the same regional variables including logarithm of per capita GDP, share of agriculture in the economy, and logarithm of employed population.

\subsection{MW spillover effect on working hours}

As we have explained earlier, Neumark et al. (2004) propose an empirical framework to estimate the effect of minimum wage on changes of income distribution. The same framework can be used to analyze its possible effect on working time for different income groups, i.e., spillover effect on working time. Therefore, we use this method to study the different impacts of minimum wage adjustments both on wages and on working hours of employees in different income, i.e. spillover effect on working time. The estimated model is as follows: 


$$
\begin{aligned}
\frac{H_{i s t}-H_{i s t-1}}{H_{i s t-1}} & =\alpha+\sum_{k} \beta_{k} \frac{m w_{s t}-m w_{s t-1}}{m w_{s t-1}} D_{k}\left(w_{i s t-1} ; m_{s t-1}\right) \\
& +\sum_{k} \gamma_{k} \frac{m w_{s t-1}-m w_{s t-2}}{m w_{s t-2}} D_{k}\left(w_{i s t-1} ; m_{s t-1}\right) \\
& +\sum_{k}^{k} \delta_{k} D_{k}\left(w_{i s t-1} ; m_{s t-1}\right)+\sum_{k} \theta_{k} D_{k}\left(w_{i s t-1} ; m_{s t-1}\right) \frac{w_{s t-1}}{m w_{s t-1}} \\
& +X_{i s t} \times \pi+\text { Province }_{i s} \times \tau+\text { Year }_{i t} \times \text { Province }_{i s} \times \varphi+\varepsilon_{i s t}
\end{aligned}
$$

where subscript $i$ represents individual, $s$ stands for provinces, and $t$ for year. The dependent variable is the change rate of working hours, with $H_{\text {ist }}$ and $H_{\text {ist- } 1}$ referring to the employees' weekly working hours in current period and prior period respectively. The key independent variables of this model are the change rate of minimum wage in the current period compared with that of the prior period, and the lagged change rate of minimum wage of the last period. Specificly, $m w_{s t}, \mathrm{mw}_{s t-1}$ and $m w_{\mathrm{st}-2}$ represent the provincial minimum wage standards in the current period, the prior period, and the one before the prior period. $W_{s t-1}$ is the wage income of the prior period, and the ratio of $W_{s t-1}$ to $\mathrm{mw}_{s t-1}$ reflects the ratio of wage relative to minimum wage in the prior period. $D_{k}\left(w_{i s t-1} ; m_{S t-1}\right)$ is a set of dummy variables. As we have explained earlier, the whole sample is divided into seven groups according to the ratio of wage to lagged minimum wage. According to Neumark et al. (2004), since the highest income group is least influenced by minimum wage, and the MW impact on labor supply and demand for this group is rather indirect, we choose the group with a wage-MW ratio above $170 \%$ as the reference group in the regression and the other five groups' dummy variables are added into the model as controlled independent variables. In addition, $X_{-i s t}$ is a group of controlled variables for individual characteristics including gender, households, age, age squared, and education level; $Y_{e a r}$ and Province $_{\text {is }}$ are dummy variables for year and province respectively.

In the above model, we pay special attention to the following parameters: $\beta_{k}, \gamma_{k}, \delta_{k}$ and $\theta_{k} ; \beta_{k}$ measures the impact of increasing minimum wage in the current period on the group defined by $D_{k}\left(w_{i s t-1} ; m_{s t-1}\right) ; \gamma_{k r}$ measures the impact of increasing minimum wage in the prior period on this group; $\delta_{k}$ refers to the fixed effect of different income groups, measuring the change of working hours of other groups compared to the highest income group, or the inter-group inequality of working hours for all employees; $\theta_{k}$ refers to the inter-group distribution of working hours of employees with different income levels measured by the ratio of wage to minimum wage, across all income groups defined by $D_{k}\left(w_{\text {ist-1 }} ; m_{S t-1}\right)$.

In analyzing how minimum wage adjustment affects working hours and income, we need to consider how firms respond to such policy adjustment strategically. In a recent working paper, Maynerisy et al. (2014) find that China's minimum wage policies have increased firms' efficiency, making them adequately respond to the negative impact of MW on output and employment. The increased efficiency comes from the substitution of low efficiency firms for high efficiency firms. When faced with the shock of minimum wage increase, firms may use multiple management strategies including layoffs, increase or reduction of working hours, cutting benefits, and enhancing technologies. As our study is at the individual level, our focus is on the MW effect on workers' working hours and wage income. 
An important methodology issue in this study is measurement errors in the dependent variables. Income and working hours are measured by average values in a year while minimum wage adjustments do not always occur at the end of the year. Therefore, using annual average values do not accurately reflects changes before or after minimum wage adjustments. We solve this issue in two ways. First, we adjust the minimum wage standard by weighting it according to the number of months it covers in a year. Second, we use robust standard errors in our regression analyses to correct the effects of measurement errors of dependent variables.

\section{Results}

\subsection{Minimum wage effect on employment}

We first examine the effect of minimum wage on workers' employment status. Table 1 reports regression results for the effect of the minimum wage on employment. The main explanatory variables are the ratio of minimum wage to average income level and its lag. Column (1) lists the result for the whole sample, while columns (2) to (3) compare the results for Eastern and other regions, and columns (4) and (5) report the results for coastal and inland regions. The results indicate that minimum wage has made non-significant effects on employment regionally or nationally. As mentioned above, one of the explanations for this may be that the minimum wage level is lower than the average wage and even the equilibrium wage, thus producing little effect on equilibrium employment.

A possible explanation for the non-significant effect of MW could be due to the mobility of rural migrant workers in cities included in the sample. Once unemployed, they may leave for another place or return home, hence unable to be reflected on the impact of the minimum wage on employment. In addition, as shown by Jia (2014), an increase of minimum wage may reduce employment more for female workers. Therefore, we next test the MW effects in urban and rural areas separately, and for male and female workers separately. The results are reported in Table 2. The effects of minimum wage are not significant on employment for any of the subgroups.

Characterized by different forms of ownership, firms in China may adopt very different management policies in recruiting, layoffs, and wage setup. This may cause the

Table 1 Minimum wage effect on employment (by Region)

\begin{tabular}{llllll}
\hline & $(1)$ & $(2)$ & $(3)$ & $(4)$ & $(5)$ \\
& Whole & Eastern & Central/Western & Coastal & Inland \\
\hline mw_avg & -2.134 & 0.317 & 0.778 & 1.362 & -0.0264 \\
& $(2.241)$ & $(2.971)$ & $(1.441)$ & $(1.832)$ & $(1.531)$ \\
mw_avg-1 & $Y$ & $Y$ & $Y$ & $Y$ & $Y$ \\
Individual characteristics & $Y$ & $Y$ & $Y$ & $Y$ & $Y$ \\
Macro-economic variables, & $Y$ & $Y$ & $Y$ & $Y$ & $Y$ \\
province dummy, year dummy & & & & & \\
$N$ & 12861 & 3081 & 4358 & 3935 & 3504 \\
$R^{2}$ & 0.13 & 0.140 & 0.208 & 0.163 & 0.187 \\
\hline
\end{tabular}

mw_avg and $\mathrm{mw}_{\text {avg }} \mathrm{av}_{-1}$ represent the ratio of minimum wage to average wage and the lagged ratio respectively. Robust standard errors are in parentheses 
Table 2 Minimum wage effect on employment (by Gender and Hukou)

\begin{tabular}{|c|c|c|c|c|}
\hline & Urban & & Rural Ho & \\
\hline & Male & Female & Male & Female \\
\hline mw_avg & -5.316 & -4.770 & -0.730 & -4.598 \\
\hline & $(3.676)$ & $(4.110)$ & $(3.312)$ & $(4.080)$ \\
\hline$m w_{-} a v g_{-1}$ & Y & Y & Y & Y \\
\hline Individual characteristics & Y & Y & Y & Y \\
\hline $\begin{array}{l}\text { Macro-economic variables, } \\
\text { province dummy, year dummy }\end{array}$ & Y & Y & Y & Y \\
\hline$N$ & 4083 & 3170 & 8777 & 7131 \\
\hline Pseudo $R^{2}$ & 0.021 & 0.020 & 0.046 & 0.065 \\
\hline
\end{tabular}

Robust standard errors are in parentheses

minimum wage effect to vary for these different types of firms. Table 3 presents MW effects on employment by firm types. The results indicate that only employees in private and individual enterprises are affected significantly and negatively.

We next examine possible effects from firms' strategies of adjusting labor cost through types of employment. With a fixed number of employees, a rise in the minimum wage leads to an increase of long-run cost. Being aware of that, firms may replace regular employees with temporary workers, which can reduce the cost caused by regular employees with unsaturated workload and in the meantime offset the effect of minimum wage increase. Nevertheless, the cost of adjusting employees may limit the impact of the minimum wage on firms' employment decisions. Table 4 reports the regression results for regular, contract, or temporary workers. The results show that employment effect of minimum wage is not significant for any of the three types of workers.

\subsection{MW effect on employees' income}

The minimum wage effect on income is not easy to predict. While it can increase the income of employees who use to earn lower than the MW level, it can also reduce income for those who use to earn higher than the MW level due to the firm's intention to offset increased labor cost in the lower end. We examine the effects first for the whole sample and then by regions and other demographic groups.

Table 3 Minimum wage effect on employment (by Enterprise Type)

\begin{tabular}{lllllll}
\hline & $\begin{array}{l}\text { Government } \\
\text { agency }\end{array}$ & $\begin{array}{l}\text { Shive } \\
\text { unit }\end{array}$ & SOE & $\begin{array}{l}\text { Collective } \\
\text { firms }\end{array}$ & $\begin{array}{l}\text { Private } \\
\text { enterprises }\end{array}$ & $\begin{array}{l}\text { Foreign } \\
\text { companies }\end{array}$ \\
\hline mw_avg & 19.03 & -16.55 & 28.02 & -19.26 & $-7.616^{* *}$ & -8.731 \\
& $(13.76)$ & $(15.24)$ & $(18.20)$ & $(12.62)$ & $(3.139)$ & $(37.79)$ \\
mw_avg-1 & $Y$ & $Y$ & $Y$ & $Y$ & $Y$ & $Y$ \\
Individual characteristics & $Y$ & $Y$ & $Y$ & $Y$ & $Y$ & $Y$ \\
Macro-economic variables, province & $Y$ & $Y$ & $Y$ & $Y$ & $Y$ & $Y$ \\
dummy, year dummy & & & & & & \\
$N$ & 501 & 1632 & 853 & 797 & 5883 & 216 \\
Pseudo $R^{2}$ & 0.038 & 0.050 & 0.069 & 0.071 & 0.027 & 0.132 \\
\hline
\end{tabular}

Robust standard errors are in parentheses. ${ }^{* *}$ denotes $p<0.05$ 
Table 4 Minimum wage effect on employment (by Employment Type)

\begin{tabular}{llll}
\hline & Regular employment & Contract employment & Temporary worker \\
\hline mw_avg & -5.898 & -1.244 & 8.987 \\
& $(6.874)$ & $(9.940)$ & $(7.385)$ \\
mw_avg-1 & $Y$ & $Y$ & $Y$ \\
Individual characteristics & $Y$ & $Y$ & $Y$ \\
Macro-economic variables, & $Y$ & $Y$ & $Y$ \\
province dummy, year dummy & & & \\
$N$ & 3746 & 1526 & 2019 \\
Pseudo $R^{2}$ & 0.023 & 0.033 & 0.017 \\
\hline
\end{tabular}

Robust standard errors are in parentheses

Table 5 reports the results of the whole sample and by regions. As shown in column (1), the minimum wage variables do not have significant effect on average income for the whole sample. We also perform the same analysis for different regions and find no significant effects as shown in other columns.

We next examine the minimum wage effect on lower-income employees, with the results reported in Table 6. A rise in minimum wage increases income for the lowest income group and the high-risk group, which is in line with the results obtained by Grossman (1983); Ma et al. (2012) from different data in China. Compare these results with those in Table 5, the non-significant effect for the whole sample could be due to the fact that the effect is not significant for the high-income groups.

Table 7 reports the results of MW income effects by gender. Females with lowest income or with high risk respond strongly to the increase of minimum wage. Income of lower-paid females with rural hukou increases significantly with MW adjustment $(p<0.01)$, with a magnitude twice as much as that of males. In urban areas, minimum wage effect on income is not significant for males or females, which is probably because income level is relatively high already for these groups before MW increases.

\subsection{MW effect on working hours}

The above analyses indicate that while higher minimum wages do not result in more job losses, they increase the earnings of low-income workers. If minimum

Table 5 Minimum wage effect on income (by Region)

\begin{tabular}{llllll}
\hline & $(1)$ & $(2)$ & $(3)$ & $(4)$ & $(5)$ \\
& Whole & Eastern & Central/Western & Costal & Inland \\
\hline mw_avg & 1.433 & 0.317 & 0.778 & 1.362 & -0.0264 \\
& $(1.126)$ & $(2.971)$ & $(1.441)$ & $(1.832)$ & $(1.531)$ \\
mw_avg_1 & $Y$ & $Y$ & $Y$ & $Y$ & $Y$ \\
Individual characteristics & $Y$ & $Y$ & $Y$ & $Y$ & $Y$ \\
Macro-economic variables, province dummy, year dummy & $Y$ & $Y$ & $Y$ & $Y$ & $Y$ \\
$N$ & 4498 & 6126 & 12485 & 8637 & 9974 \\
$R^{2}$ & 0.187 & 0.046 & 0.010 & 0.041 & 0.014 \\
\hline
\end{tabular}

Robust standard errors are in parentheses 
Table 6 Minimum wage effect on income (by Income Level)

\begin{tabular}{lll}
\hline & People with lowest income & People at risk \\
\hline mw_avg & $5.665^{* * *}$ & $2.874^{* * *}$ \\
& $(1.502)$ & $(0.275)$ \\
mw_avg $_{-1}$ & $Y$ & $Y$ \\
Individual characteristics & $Y$ & $Y$ \\
Macro-economic variables, & $Y$ & $Y$ \\
province dummy, year dummy & & \\
$N$ & 953 & 647 \\
$R^{2}$ & 0.283 & 0.951 \\
\hline
\end{tabular}

The lowest income group refers to those within the $90 \%$ of minimum wage level. Robust standard errors are in parentheses. ${ }^{* * *}$ denotes $p<0.01$

wage increases firms' labor cost, how do they respond to it? Since staff turnover can lead to higher costs, the employer may find it more desirable to cut working hours to offset the rise of minimum wage instead of cutting the number of staff. The minimum wage effect on working hours can be of crucial importance and may exist for two reasons. First, due to weak enforcement and loopholes in laws and regulations, some employers may increase working hours in one way or another in order to make up the cost increase resulted from meeting the minimum standard. Second, since the government has set definite minimum hourly wages since 2007, some employers may reconsider their policies on staffing size, working hours, and types of employment (permanent staff, contract workers, temporary workers, etc.), and cut down high-cost working hours in order to reduce labor cost.

Table 8 reports the results of our analysis for working time. The results seem to support the second point above: an increased minimum wage leads to a general decline of working hours for Chinese workers, which is consistent with the findings of Machin et al. (2003); Stewart and Swaffield (2008).

We next compare the MW effect on working time for urban and rural labor forces. Table 9 shows that, the decline in working hours of rural workers is greater than that of the urban ones, and that working hours are reduced more for rural female workers than for their male counterparts. These may suggest that setting minimum wages has caused the employers to alter their working arrangements, and has led to better pays, and fewer working hours.

Table 7 Minimum wage effect on income (by Gender and Hukou)

\begin{tabular}{|c|c|c|c|c|c|c|}
\hline & \multicolumn{2}{|l|}{ Whole } & \multicolumn{2}{|c|}{ Urban Hukou } & \multicolumn{2}{|c|}{ Rural Hukou } \\
\hline & Male & Female & Male & female & male & Female \\
\hline \multirow[t]{2}{*}{ mw_avg } & 1.433 & $2.242^{*}$ & 1.225 & 0.269 & 2.501 & $5.683^{* * *}$ \\
\hline & $(1.126)$ & $(1.285)$ & $(1.356)$ & $(1.549)$ & $(1.922)$ & $(2.132)$ \\
\hline mw_avg-1 & Y & Y & Y & Y & Y & Y \\
\hline Individual characteristics & Y & Y & Y & Y & Y & Y \\
\hline Macro-economic variables, province dummy, year dummy & Y & Y & Y & Y & Y & $Y$ \\
\hline$N$ & 4498 & 2940 & 2615 & 1861 & 1882 & 1079 \\
\hline$R^{2}$ & 0.187 & 0.184 & 0.195 & 0.225 & 0.198 & 0.204 \\
\hline
\end{tabular}

Robust standard errors are in parentheses. ${ }^{*}$ denotes $p<0.10,{ }^{* * *}$ denotes $p<0.01$ 
Table 8 Minimum wage effect on work time (by Region)

\begin{tabular}{llll}
\hline & $(1)$ & $(2)$ & $(3)$ \\
& Whole & Eastern & Central/Western \\
\hline mw_avg & $-2.073^{* *}$ & $-7.102^{* * *}$ & $-1.758^{*}$ \\
& $(0.834)$ & $(2.533)$ & $(1.011)$ \\
mw_avg-1 & $Y$ & $Y$ & $Y$ \\
Individual characteristics & $Y$ & $Y$ & $Y$ \\
Macro-economic variables, province dummy, year dummy & $Y$ & $Y$ & $Y$ \\
$N$ & 10500 & 3081 & 4358 \\
$R^{2}$ & 0.020 & 0.140 & 0.208 \\
\hline
\end{tabular}

Robust standard errors are in parentheses. ${ }^{*}$ denotes $p<0.10,{ }^{* *}$ denotes $p<0.05,{ }^{* * *}$ denotes $p<0.01$

\subsection{Spillover effect on working hours}

The above analysis shows that increase of minimum wage shortens average working hours. In this section, we investigate whether MW increase also has a distribution or spillover effect on working hours as it does to workers' income (Stewart, 2012). It is possible that when minimum wage is increased, due to management's adjustments, working loads or hours of certain income groups are significantly increased while other groups are not significantly affected.

We use the same method of Neumark et al. (2004) as we used in section 3.2 when analyzing MW effect on income. The dependent variable is now the working hours of a worker. The target sample contains only employed workers. We perform the analysis for the whole sample and for different groups. For group analysis, we divide the whole sample according to worker's gender, hukou status, type of firm a worker is employed for, type of employment contract, and the region of residence.

Our main estimation interest is the interaction of minimum wage change and the dummy of a worker's income group. The results indicate the following: minimum wage adjustment does not have significant effect on the relative working hours for different income groups; the results are similar when the analysis is conducted by gender, hukou, contract type, and regions. Two explanations are possible for this finding. First, while increase of minimum wage directly increases the labor cost for employment of low wage workers, it could have indirectly increased the labor cost for the whole labor force, thus reduced average working hours. Second, reference effect between workers can lead to the reduction of average working hours for the whole labor force when workers compare themselves with hours of others.

Table 9 Minimum wage effect on work time (by Gender and Hukou)

\begin{tabular}{|c|c|c|c|c|c|c|}
\hline & \multicolumn{2}{|l|}{ Whole } & \multicolumn{2}{|c|}{ Urban Hukou } & \multicolumn{2}{|c|}{ Rural Hukou } \\
\hline & Male & Female & Male & Female & male & female \\
\hline \multirow[t]{2}{*}{ mw_avg } & $-2.073^{* *}$ & $-3.425^{* * *}$ & $-1.834^{* *}$ & $-1.885^{*}$ & $-2.064^{*}$ & $-3.648^{* * *}$ \\
\hline & $(0.834)$ & $(1.013)$ & $(0.932)$ & $(1.129)$ & $(1.164)$ & $(1.351)$ \\
\hline mw_avg-1 & Y & Y & Y & Y & Y & Y \\
\hline Individual characteristics & Y & Y & Y & Y & Y & Y \\
\hline $\begin{array}{l}\text { Macro-economic variables, province dummy, } \\
\text { year dummy }\end{array}$ & Y & Y & Y & Y & Y & Y \\
\hline N & 10500 & 8110 & 3271 & 2385 & 7228 & 5725 \\
\hline$R^{2}$ & 0.020 & 0.027 & 0.014 & 0.021 & 0.021 & 0.033 \\
\hline
\end{tabular}


In the analysis by firm type, we find that only in collective business firms, working hours of low wage workers are significantly lowered by minimum wage adjustment. Hours distributions in other firm types including government agency, state owned public units, state owned business, and private business are not significantly affected. The income of workers is lowest in collective business compared with those in other firms. Since collective business has the most flexible employment institution, minimum wage may affect working hours of the low wage workers the strongest in these firms.

There are many possible ways of dividing a target group into different income groups. Considering that dividing into too many groups may reduce the sample size in each group, we eventually choose to report the results of dividing the sample into three income groups: lower than $110 \%$ of MW, between 110 and $170 \%$ of MW, and higher than $170 \%$ of MW. Table 10 shows the results by division of income and by firm type. Other estimations for the whole sample and for groups are omitted as we have summarized the main findings and do not find significant MW distribution effect on working hours.

\section{Robustness check}

In the above analyses of minimum wage effect on employment, wages, and working hours, we have followed previous literature and have used minimum wage standards adjusted by coverage months as the explanatory variables. However, the boundary of such adjustments is not clear cut. We check the robustness of the results by substituting the logarithms of the absolute values of the current and previous minimum wages for the previous two explanatory variables. We report only the results by genders in Table $11 .^{2}$

With previous minimum wage controlled for, the minimum wage adjustment does not affect employment significantly, but increases wage significantly, and slightly more so for females than for males. The last two columns show that minimum wage increase significantly reduces working hours for females by $4.7 \%$, but does not affect male workers' hours significantly. Thus the result of the robustness check is largely consistent with our earlier analyses and supports similar conclusions.

\section{Conclusion}

This paper investigates the minimum wage effect on employment, wages, and working hours using a pre-specified model controlling minimum wage of the previous period,

Table 10 Spillover effects of MW on working hours(by Firm Type)

\begin{tabular}{lllllll}
\hline & $(1)$ & $(2)$ & $(3)$ & $(4)$ & $(5)$ & $(6)$ \\
\hline$<110 \% \mathrm{MW}$ & 8.234 & -1.225 & 1.135 & $-1.961^{*}$ & 1.672 & -6.162 \\
& $(9.749)$ & $(0.944)$ & $(1.149)$ & $(1.133)$ & $(1.665)$ & $(6.030)$ \\
$110-170 \% \mathrm{MW}$ & 41.34 & -0.393 & -0.612 & 1.272 & 0.567 & 1.222 \\
& $(37.94)$ & $(0.462)$ & $(0.465)$ & $(1.659)$ & $(1.442)$ & $(2.258)$ \\
Control variables & $Y$ & $Y$ & $Y$ & $Y$ & $Y$ & $Y$ \\
_cons & -18.61 & $-1.446^{* * *}$ & -0.116 & $-1.408^{*}$ & -1.093 & -5.185 \\
& $(15.12)$ & $(0.413)$ & $(0.717)$ & $(0.820)$ & $(1.985)$ & $(4.540)$ \\
$N$ & 164 & 654 & 252 & 220 & 601 & 61 \\
$R^{2}$ & 0.195 & 0.058 & 0.147 & 0.156 & 0.093 & 0.326 \\
\hline Columns (1)-(6): (1) government agency; (2) state non-business; (3) state corporate business; (4) collective business; (5) \\
individually owned business; (6) joint-ventures and others. Robust standard errors in parentheses. ${ }^{*} p<0.10{ }^{* * *} p<0.01$
\end{tabular}


Table 11 Robustness check

\begin{tabular}{|c|c|c|c|c|c|c|}
\hline & \multicolumn{2}{|c|}{ Employment } & \multicolumn{2}{|l|}{ Income } & \multicolumn{2}{|c|}{ Working hours } \\
\hline & Male & Female & Male & Female & Male & Female \\
\hline \multirow[t]{2}{*}{ Lnmw } & -0.201 & -0.822 & $0.604^{* *}$ & $0.816^{* * *}$ & -0.293 & $-0.473^{*}$ \\
\hline & $(0.543)$ & $(0.626)$ & $(0.280)$ & $(0.304)$ & $(0.209)$ & $(0.253)$ \\
\hline $\mathrm{Inmw}_{-1}$ & Y & Y & Y & Y & Y & Y \\
\hline Individual characteristics & Y & Y & Y & Y & Y & Y \\
\hline Macro-economic variables, province dummy, year dummy & Y & Y & Y & Y & $Y$ & $Y$ \\
\hline$N$ & 12861 & 10301 & 4498 & 2940 & 10500 & 8110 \\
\hline$R^{2}$ & 0.027 & 0.027 & 0.188 & 0.185 & 0.019 & 0.026 \\
\hline
\end{tabular}

individual characteristics, provincial characteristics, and fixed effects of provinces and years. We find that minimum wages have contributions to wage increases, especially for lowincome workers, such as female workers and those with rural hukou. Increase of minimum wage has negative employment effect only for workers in private and individual enterprises. Minimum wage adjustments have also significantly reduced working hours of employed workers, especially for women. This implies that, without significant impact on total production, minimum wages have the potential of increasing the welfare for the low-income workers.

\section{Endnotes}

${ }^{1}$ There are few existing surveys that contain information about working hours. Another survey with such information is RUMIC (Rural-urban Migration in China) with which we have obtained an average of 59 weekly working hours. Since RUMIC focuses on migrant workers, the difference between the two data sets implies that migrant workers work longer hours than the average of those workers in CHNS that include both migrant workers and urban workers. Workers in both data sets work longer than the legal cap $40 \mathrm{~h}$ probably because they contain migrant workers.

${ }^{2}$ All the analyses for different subgroups we performed earlier stood the robustness check. Given the limited space, only regression results classified by gender are listed in the table.

\section{Appendix}

Table 12 Ratio of minimum wage to average wage by region (2004-2011)

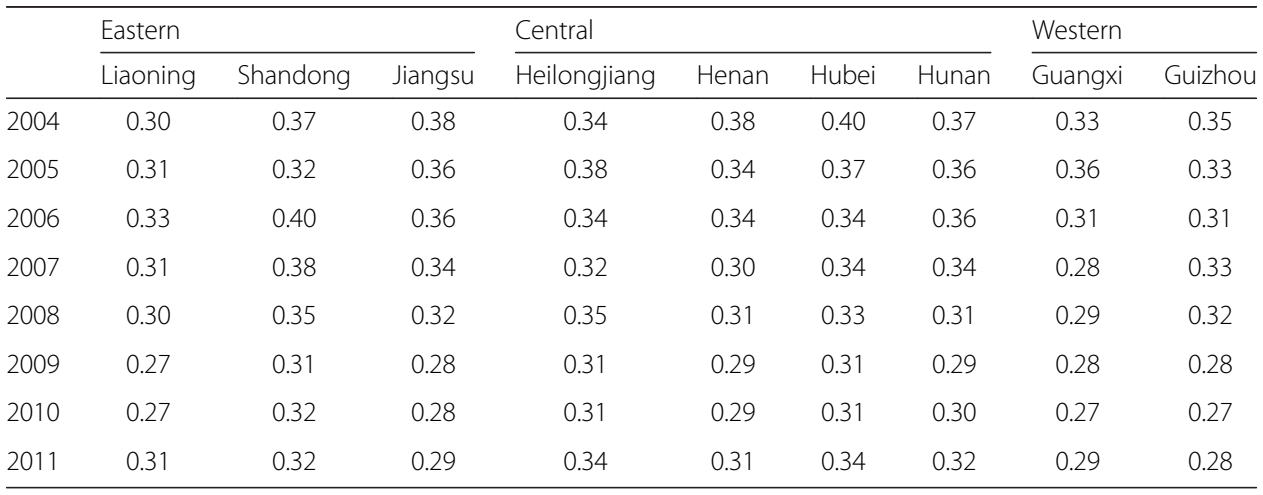


Table 13 Descriptive statistics

\begin{tabular}{|c|c|c|c|c|c|}
\hline & & $\begin{array}{l}\text { Proportion of employed } \\
\text { in population }\end{array}$ & Monthly wage & $\begin{array}{l}\text { Weekly working } \\
\text { hours }\end{array}$ & $\begin{array}{l}\text { Minimum wage/ } \\
\text { average wage }\end{array}$ \\
\hline \multicolumn{2}{|c|}{ Whole sample } & $42.27 \%$ & 1478.9 & 43.5 & $32.33 \%$ \\
\hline \multicolumn{6}{|l|}{ Waves } \\
\hline \multicolumn{2}{|l|}{2004} & $50.07 \%$ & 861.8 & 43.6 & $35.90 \%$ \\
\hline \multicolumn{2}{|l|}{2006} & $40.73 \%$ & 1072.9 & 44.6 & $34.11 \%$ \\
\hline \multicolumn{2}{|l|}{2009} & $40.11 \%$ & 1717.8 & 43.3 & $28.97 \%$ \\
\hline \multicolumn{2}{|l|}{2011} & $39.13 \%$ & 2109.5 & 42.6 & $30.79 \%$ \\
\hline \multicolumn{6}{|l|}{ Gender } \\
\hline \multicolumn{2}{|l|}{ Male } & $47.72 \%$ & 1609.2 & 43.6 & $32.40 \%$ \\
\hline \multicolumn{2}{|l|}{ Female } & $36.99 \%$ & 1289.2 & 43.4 & $32.27 \%$ \\
\hline \multicolumn{6}{|l|}{ Hukou $^{a}$} \\
\hline \multicolumn{2}{|l|}{ Urban } & $51.89 \%$ & 1572.2 & 42.5 & $32.60 \%$ \\
\hline \multicolumn{2}{|l|}{ Rural } & $70.66 \%$ & 1282.4 & 45.2 & $32.48 \%$ \\
\hline \multicolumn{6}{|l|}{ Age cohorts } \\
\hline \multicolumn{2}{|l|}{$16-29$} & $75.72 \%$ & 1672.4 & 45.6 & $32.74 \%$ \\
\hline \multicolumn{2}{|l|}{$30-39$} & $82.73 \%$ & 1426.2 & 44.7 & $32.83 \%$ \\
\hline \multicolumn{2}{|l|}{$40-49$} & $80.78 \%$ & 1623.5 & 43.5 & $32.60 \%$ \\
\hline \multicolumn{2}{|l|}{$50-59$} & $64.03 \%$ & 1603.2 & 41.9 & $32.55 \%$ \\
\hline \multicolumn{2}{|l|}{$60-65$} & $44.08 \%$ & 1389.7 & 42.8 & $32.19 \%$ \\
\hline \multicolumn{6}{|c|}{ Education attainment } \\
\hline \multicolumn{2}{|l|}{ Illiteracy } & $38.25 \%$ & 943.6 & 39.9 & $32.55 \%$ \\
\hline \multicolumn{2}{|l|}{ Primary } & $69.34 \%$ & 1096.0 & 42.3 & $32.43 \%$ \\
\hline \multicolumn{2}{|c|}{ Junior high school } & $71.23 \%$ & 1369.1 & 45.3 & $32.54 \%$ \\
\hline \multicolumn{2}{|c|}{ Senior high school } & $69.73 \%$ & 1457.8 & 41.9 & $32.97 \%$ \\
\hline \multicolumn{2}{|c|}{ Vocational college } & $66.80 \%$ & 1478.7 & 42.3 & $32.87 \%$ \\
\hline University & or above & $75.36 \%$ & 2101.0 & 39.8 & $32.65 \%$ \\
\hline Region & & & & & \\
\hline Eastern & Shandong & $42.21 \%$ & 1344.6 & 33.28 & $42.21 \%$ \\
\hline & Liaoning & $42.00 \%$ & 1594.8 & 30.19 & $42.00 \%$ \\
\hline & Jiangsu & $49.22 \%$ & 1480.3 & 32.84 & $49.22 \%$ \\
\hline Central & Hunan & $34.56 \%$ & 1738.7 & 33.30 & $34.56 \%$ \\
\hline & Hubei & $38.48 \%$ & 1369.3 & 34.90 & $38.48 \%$ \\
\hline & Henan & $40.95 \%$ & 1249.4 & 32.53 & $40.95 \%$ \\
\hline & Heilongjiang & $53.74 \%$ & 1865.3 & 34.77 & $53.74 \%$ \\
\hline Western & Guizhou & $39.60 \%$ & 1612.8 & 30.31 & $39.60 \%$ \\
\hline & Guangxi & $43.44 \%$ & 1046.3 & 30.21 & $43.44 \%$ \\
\hline Employment & type & & & & \\
\hline Regular & & - & 1638.2 & 42.2 & $32.81 \%$ \\
\hline Contract & & - & 1363.6 & 43.4 & $31.93 \%$ \\
\hline Temporar) & & - & 1118.2 & 46.2 & $32.13 \%$ \\
\hline Enterprise & & & & & \\
\hline Governme & & - & 1630.0 & 38.1 & $32.48 \%$ \\
\hline Shiye unit & & - & 1836.7 & 39.4 & $32.73 \%$ \\
\hline SOE & & - & 1411.9 & 42.7 & $33.11 \%$ \\
\hline
\end{tabular}


Table 13 Descriptive statistics (Continued)

\begin{tabular}{lllll}
\hline Collective firms & - & 1258.6 & 44.6 & $33.07 \%$ \\
Private firms & - & 1296.6 & 46.5 & $32.60 \%$ \\
Foreign enterprises & - & 1491.8 & 43.9 & $32.13 \%$ \\
\hline
\end{tabular}

${ }^{a}$ Note that in the whole sample of 74750 observations, there are 24975 of them who are missing information about Hukou, which is why the proportion counts in this category are higher than the average of the whole sample

Table 14 Demographic summary by income level

\begin{tabular}{|c|c|c|c|c|c|c|c|c|c|}
\hline & & Observation & $<90 \%$ & 90-110\% & 110-130\% & 130-150\% & 150-170\% & 170-190\% & $\begin{array}{l}190 \% \\
\text { above }\end{array}$ \\
\hline \multicolumn{2}{|c|}{ Whole sample } & 15159 & $13.02 \%$ & $8.49 \%$ & $8.78 \%$ & $10.28 \%$ & $6.65 \%$ & $10.43 \%$ & $42.35 \%$ \\
\hline \multicolumn{10}{|l|}{ Waves } \\
\hline \multicolumn{2}{|l|}{2004} & 3336 & $13.77 \%$ & $7.93 \%$ & $7.73 \%$ & $9.33 \%$ & $7.10 \%$ & $9.52 \%$ & $44.61 \%$ \\
\hline \multicolumn{2}{|l|}{2006} & 3484 & $14.68 \%$ & $9.36 \%$ & $9.67 \%$ & $10.34 \%$ & $7.43 \%$ & $11.95 \%$ & $36.57 \%$ \\
\hline \multicolumn{2}{|l|}{2009} & 4172 & $11.35 \%$ & $7.75 \%$ & $10.39 \%$ & $10.54 \%$ & $6.29 \%$ & $8.78 \%$ & $44.90 \%$ \\
\hline \multicolumn{2}{|l|}{2011} & 4167 & $12.67 \%$ & $8.93 \%$ & $7.24 \%$ & $10.70 \%$ & $5.97 \%$ & $11.51 \%$ & $42.97 \%$ \\
\hline \multicolumn{10}{|l|}{ Gender } \\
\hline \multicolumn{2}{|l|}{ Male } & 9598 & $8.91 \%$ & $6.26 \%$ & $7.70 \%$ & $9.83 \%$ & $6.61 \%$ & $11.52 \%$ & $49.17 \%$ \\
\hline \multicolumn{2}{|l|}{ Female } & 5559 & $19.28 \%$ & $11.88 \%$ & $10.42 \%$ & $10.95 \%$ & $6.68 \%$ & $8.78 \%$ & $31.99 \%$ \\
\hline \multicolumn{10}{|l|}{ Hukou } \\
\hline \multicolumn{2}{|l|}{ Urban } & 9856 & $9.77 \%$ & $7.27 \%$ & $7.69 \%$ & $8.74 \%$ & $6.05 \%$ & $10.10 \%$ & $50.39 \%$ \\
\hline \multicolumn{2}{|l|}{ Rural } & 5294 & $18.36 \%$ & $10.52 \%$ & $10.57 \%$ & $12.83 \%$ & $7.65 \%$ & $10.97 \%$ & $29.10 \%$ \\
\hline \multicolumn{10}{|l|}{ Age cohort } \\
\hline \multicolumn{2}{|l|}{$16-29$} & 2526 & $9.18 \%$ & $8.18 \%$ & $11.49 \%$ & $13.48 \%$ & $10.36 \%$ & $13.73 \%$ & $33.58 \%$ \\
\hline \multicolumn{2}{|l|}{$30-39$} & 3990 & $10.80 \%$ & $8.75 \%$ & $7.66 \%$ & $11.97 \%$ & $6.89 \%$ & $12.25 \%$ & $41.68 \%$ \\
\hline \multicolumn{2}{|l|}{$40-49$} & 5240 & $12.67 \%$ & $8.34 \%$ & $9.04 \%$ & $8.77 \%$ & $5.69 \%$ & $9.29 \%$ & $46.20 \%$ \\
\hline \multicolumn{2}{|l|}{$50-59$} & 2932 & $15.30 \%$ & $8.17 \%$ & $7.57 \%$ & $8.22 \%$ & $5.26 \%$ & $7.95 \%$ & $47.53 \%$ \\
\hline \multicolumn{2}{|l|}{$60-65$} & 313 & $34.20 \%$ & $13.85 \%$ & $8.66 \%$ & $7.79 \%$ & $3.46 \%$ & $5.63 \%$ & $26.41 \%$ \\
\hline \multicolumn{10}{|c|}{ Education attainment } \\
\hline \multicolumn{2}{|l|}{ Illiteracy } & 179 & $40.28 \%$ & $16.67 \%$ & $8.33 \%$ & $10.42 \%$ & $4.17 \%$ & $4.17 \%$ & $15.97 \%$ \\
\hline \multicolumn{2}{|l|}{ Primary } & 1609 & $27.02 \%$ & $12.02 \%$ & $12.45 \%$ & $11.34 \%$ & $6.05 \%$ & $8.95 \%$ & $22.17 \%$ \\
\hline \multicolumn{2}{|c|}{ Junior high school } & 4886 & $16.09 \%$ & $10.39 \%$ & $11.06 \%$ & $12.72 \%$ & $7.48 \%$ & $11.34 \%$ & $30.92 \%$ \\
\hline \multicolumn{2}{|c|}{ Senior high school } & 2997 & $11.45 \%$ & $9.65 \%$ & $9.28 \%$ & $10.71 \%$ & $7.26 \%$ & $11.24 \%$ & $40.40 \%$ \\
\hline \multicolumn{2}{|c|}{ Vocational college } & 2605 & $6.30 \%$ & $4.96 \%$ & $5.57 \%$ & $8.45 \%$ & $7.18 \%$ & $11.13 \%$ & $56.41 \%$ \\
\hline \multicolumn{2}{|c|}{ University or above } & 2858 & $1.69 \%$ & $3.06 \%$ & $3.71 \%$ & $5.60 \%$ & $4.29 \%$ & $8.39 \%$ & $73.26 \%$ \\
\hline \multicolumn{10}{|l|}{ Region } \\
\hline \multirow[t]{3}{*}{ Eastern } & Shandong & 1723 & $14.50 \%$ & $10.98 \%$ & $8.17 \%$ & $14.94 \%$ & $7.91 \%$ & $11.42 \%$ & $32.07 \%$ \\
\hline & Liaoning & 1855 & $12.06 \%$ & $7.60 \%$ & $6.08 \%$ & $8.49 \%$ & $8.13 \%$ & $8.94 \%$ & $48.70 \%$ \\
\hline & Jiangsu & 2480 & $21.54 \%$ & $9.32 \%$ & $11.28 \%$ & $10.68 \%$ & $3.68 \%$ & $14.48 \%$ & $29.02 \%$ \\
\hline Central & Hunan & 1556 & $6.17 \%$ & $5.39 \%$ & $7.86 \%$ & $5.95 \%$ & $8.75 \%$ & $10.44 \%$ & $55.44 \%$ \\
\hline & Hubei & 1496 & $11.33 \%$ & $9.06 \%$ & $8.20 \%$ & $10.03 \%$ & $7.44 \%$ & $8.74 \%$ & $45.20 \%$ \\
\hline & Henan & 1403 & $12.70 \%$ & $8.58 \%$ & $9.61 \%$ & $8.58 \%$ & $9.73 \%$ & $9.38 \%$ & $41.42 \%$ \\
\hline & Heilongjiang & 1797 & $5.78 \%$ & $3.78 \%$ & $5.18 \%$ & $6.27 \%$ & $3.49 \%$ & $9.96 \%$ & $65.54 \%$ \\
\hline
\end{tabular}


Table 14 Demographic summary by income level (Continued)

\begin{tabular}{|c|c|c|c|c|c|c|c|c|c|}
\hline \multirow[t]{2}{*}{ Western } & Guizhou & 1318 & $7.37 \%$ & $7.62 \%$ & $7.75 \%$ & $9.78 \%$ & $6.10 \%$ & $8.39 \%$ & $52.99 \%$ \\
\hline & Guangxi & 1531 & $17.36 \%$ & $12.47 \%$ & $13.02 \%$ & $15.79 \%$ & $6.83 \%$ & $8.86 \%$ & $25.67 \%$ \\
\hline \multicolumn{10}{|c|}{ Employment type } \\
\hline \multicolumn{2}{|l|}{ Regular } & 8001 & $7.14 \%$ & $5.44 \%$ & $6.13 \%$ & $8.63 \%$ & $6.73 \%$ & $10.32 \%$ & $55.61 \%$ \\
\hline \multicolumn{2}{|l|}{ Contract } & 2422 & $12.77 \%$ & $9.04 \%$ & $11.69 \%$ & $13.40 \%$ & $6.89 \%$ & $13.97 \%$ & $32.24 \%$ \\
\hline \multicolumn{2}{|c|}{ Temporary } & 2191 & $24.53 \%$ & $16.70 \%$ & $12.99 \%$ & $12.75 \%$ & $6.62 \%$ & $8.26 \%$ & $18.15 \%$ \\
\hline \multicolumn{10}{|l|}{ Enterprise } \\
\hline \multicolumn{2}{|c|}{ Government } & 1027 & $14.09 \%$ & $4.92 \%$ & $6.28 \%$ & $0.34 \%$ & $6.79 \%$ & $7.47 \%$ & $60.10 \%$ \\
\hline \multicolumn{2}{|c|}{ Shiye unit } & 3600 & $5.07 \%$ & $3.21 \%$ & $3.78 \%$ & $1.60 \%$ & $4.76 \%$ & $7.82 \%$ & $73.76 \%$ \\
\hline \multicolumn{2}{|l|}{ SOE } & 1867 & $8.78 \%$ & $7.54 \%$ & $9.66 \%$ & $8.51 \%$ & $7.27 \%$ & $12.06 \%$ & $46.19 \%$ \\
\hline \multicolumn{2}{|c|}{ Collective firms } & 1323 & $17.63 \%$ & $13.14 \%$ & $10.62 \%$ & $13.69 \%$ & $7.67 \%$ & $13.36 \%$ & $23.88 \%$ \\
\hline \multicolumn{2}{|c|}{ Private firms } & 5517 & $14.71 \%$ & $10.19 \%$ & $11.36 \%$ & $13.41 \%$ & $7.08 \%$ & $10.95 \%$ & $32.29 \%$ \\
\hline \multicolumn{2}{|c|}{ Foreign enterprises } & 408 & $5.95 \%$ & $7.54 \%$ & $11.51 \%$ & $13.10 \%$ & $8.33 \%$ & $20.63 \%$ & $32.94 \%$ \\
\hline
\end{tabular}

$<90 \%, 90-110 \%, 110-130 \%, 130-150 \%, 150-170 \%, 170-190 \%$ and $190 \%$ above denote the ratios of minimum wage to monthly wage

Table 15 2004-2011 monthly minimum wage standard

\begin{tabular}{|c|c|c|c|c|c|c|c|c|c|c|}
\hline \multirow[t]{2}{*}{ Year } & \multirow[t]{2}{*}{ Month } & \multicolumn{3}{|l|}{ Eastern } & \multicolumn{4}{|l|}{ Central } & \multicolumn{2}{|l|}{ Western } \\
\hline & & Liaoning & Shandong & Jiangsu & Heilongjiang & Henan & Hubei & Hunan & Guangxi & Guizhou \\
\hline \multirow[t]{12}{*}{2004} & 1 & 360 & 410 & 540 & 390 & 380 & 400 & 400 & 340 & 350 \\
\hline & 2 & 360 & 410 & 540 & 390 & 380 & 400 & 400 & 340 & 350 \\
\hline & 3 & 360 & 410 & 540 & 390 & 380 & 400 & 400 & 340 & 350 \\
\hline & 4 & 360 & 410 & 540 & 390 & 380 & 400 & 400 & 340 & 350 \\
\hline & 5 & 360 & 410 & 540 & 390 & 380 & 400 & 400 & 340 & 350 \\
\hline & 6 & 360 & 410 & 540 & 390 & 380 & 400 & 400 & 340 & 350 \\
\hline & 7 & 360 & 410 & 620 & 390 & 380 & 400 & 460 & 340 & 350 \\
\hline & 8 & 360 & 410 & 620 & 390 & 380 & 400 & 460 & 340 & 350 \\
\hline & 9 & 360 & 410 & 620 & 390 & 380 & 400 & 460 & 340 & 350 \\
\hline & 10 & 360 & 410 & 620 & 390 & 380 & 400 & 460 & 460 & 400 \\
\hline & 11 & 450 & 410 & 620 & 390 & 380 & 400 & 460 & 460 & 400 \\
\hline & 12 & 450 & 410 & 620 & 390 & 380 & 400 & 460 & 460 & 400 \\
\hline \multirow[t]{11}{*}{2005} & 1 & 450 & 530 & 620 & 390 & 380 & 400 & 460 & 460 & 400 \\
\hline & 2 & 450 & 530 & 620 & 390 & 380 & 400 & 460 & 460 & 400 \\
\hline & 3 & 450 & 530 & 620 & 390 & 380 & 460 & 460 & 460 & 400 \\
\hline & 4 & 450 & 530 & 620 & 390 & 380 & 460 & 460 & 460 & 400 \\
\hline & 5 & 450 & 530 & 620 & 390 & 380 & 460 & 460 & 460 & 400 \\
\hline & 6 & 450 & 530 & 620 & 390 & 380 & 460 & 460 & 460 & 400 \\
\hline & 7 & 450 & 530 & 620 & 390 & 380 & 460 & 480 & 460 & 400 \\
\hline & 8 & 450 & 530 & 620 & 390 & 380 & 460 & 480 & 460 & 400 \\
\hline & 9 & 450 & 530 & 620 & 390 & 380 & 460 & 480 & 460 & 400 \\
\hline & 10 & 450 & 530 & 620 & 390 & 480 & 460 & 480 & 460 & 400 \\
\hline & 11 & 450 & 530 & 690 & 390 & 480 & 460 & 480 & 460 & 400 \\
\hline
\end{tabular}


Table 15 2004-2011 monthly minimum wage standard (Continued)

\begin{tabular}{|c|c|c|c|c|c|c|c|c|c|c|}
\hline & 12 & 450 & 530 & 690 & 390 & 480 & 460 & 480 & 460 & 400 \\
\hline \multirow[t]{12}{*}{2006} & 1 & 450 & 530 & 690 & 390 & 480 & 460 & 480 & 460 & 400 \\
\hline & 2 & 450 & 530 & 690 & 390 & 480 & 460 & 480 & 460 & 400 \\
\hline & 3 & 450 & 530 & 690 & 390 & 480 & 460 & 480 & 460 & 400 \\
\hline & 4 & 450 & 530 & 690 & 390 & 480 & 460 & 480 & 460 & 400 \\
\hline & 5 & 450 & 530 & 690 & 620 & 480 & 460 & 480 & 460 & 400 \\
\hline & 6 & 590 & 530 & 690 & 620 & 480 & 460 & 480 & 460 & 400 \\
\hline & 7 & 590 & 530 & 690 & 620 & 480 & 460 & 600 & 460 & 400 \\
\hline & 8 & 590 & 530 & 690 & 620 & 480 & 460 & 600 & 460 & 400 \\
\hline & 9 & 590 & 530 & 690 & 620 & 480 & 460 & 600 & 500 & 400 \\
\hline & 10 & 590 & 610 & 750 & 620 & 480 & 460 & 600 & 500 & 550 \\
\hline & 11 & 590 & 610 & 750 & 620 & 480 & 460 & 600 & 500 & 550 \\
\hline & 12 & 590 & 610 & 750 & 620 & 480 & 460 & 600 & 500 & 550 \\
\hline \multirow[t]{12}{*}{2007} & 1 & 590 & 610 & 750 & 620 & 480 & 460 & 600 & 500 & 550 \\
\hline & 2 & 590 & 610 & 750 & 620 & 480 & 460 & 600 & 500 & 550 \\
\hline & 3 & 590 & 610 & 750 & 620 & 480 & 580 & 600 & 500 & 550 \\
\hline & 4 & 590 & 610 & 750 & 620 & 480 & 580 & 600 & 500 & 550 \\
\hline & 5 & 590 & 610 & 750 & 620 & 480 & 580 & 600 & 500 & 550 \\
\hline & 6 & 590 & 610 & 750 & 620 & 480 & 580 & 600 & 500 & 550 \\
\hline & 7 & 590 & 610 & 750 & 620 & 480 & 580 & 635 & 500 & 550 \\
\hline & 8 & 590 & 610 & 750 & 620 & 480 & 580 & 635 & 500 & 550 \\
\hline & 9 & 590 & 610 & 750 & 620 & 480 & 580 & 635 & 500 & 550 \\
\hline & 10 & 590 & 610 & 850 & 620 & 650 & 580 & 635 & 500 & 550 \\
\hline & 11 & 590 & 610 & 850 & 620 & 650 & 580 & 635 & 580 & 650 \\
\hline & 12 & 590 & 610 & 850 & 620 & 650 & 580 & 635 & 580 & 650 \\
\hline \multirow[t]{12}{*}{2008} & 1 & 700 & 760 & 850 & 680 & 650 & 580 & 635 & 580 & 650 \\
\hline & 2 & 700 & 760 & 850 & 680 & 650 & 580 & 635 & 580 & 650 \\
\hline & 3 & 700 & 760 & 850 & 680 & 650 & 580 & 635 & 580 & 650 \\
\hline & 4 & 700 & 760 & 850 & 680 & 650 & 580 & 635 & 580 & 650 \\
\hline & 5 & 700 & 760 & 850 & 680 & 650 & 580 & 635 & 580 & 650 \\
\hline & 6 & 700 & 760 & 850 & 680 & 650 & 580 & 635 & 580 & 650 \\
\hline & 7 & 700 & 760 & 850 & 680 & 650 & 580 & 665 & 580 & 650 \\
\hline & 8 & 700 & 760 & 850 & 680 & 650 & 700 & 665 & 670 & 650 \\
\hline & 9 & 700 & 760 & 850 & 680 & 650 & 700 & 665 & 670 & 650 \\
\hline & 10 & 700 & 760 & 850 & 680 & 650 & 700 & 665 & 670 & 650 \\
\hline & 11 & 700 & 760 & 850 & 680 & 650 & 700 & 665 & 670 & 650 \\
\hline & 12 & 700 & 760 & 850 & 680 & 650 & 700 & 665 & 670 & 650 \\
\hline \multirow[t]{8}{*}{2009} & 1 & 700 & 760 & 850 & 680 & 650 & 700 & 665 & 670 & 650 \\
\hline & 2 & 700 & 760 & 850 & 680 & 650 & 700 & 665 & 670 & 650 \\
\hline & 3 & 700 & 760 & 850 & 680 & 650 & 700 & 665 & 670 & 650 \\
\hline & 4 & 700 & 760 & 850 & 680 & 650 & 700 & 665 & 670 & 650 \\
\hline & 5 & 700 & 760 & 850 & 680 & 650 & 700 & 665 & 670 & 650 \\
\hline & 6 & 700 & 760 & 850 & 680 & 650 & 700 & 665 & 670 & 650 \\
\hline & 7 & 700 & 760 & 850 & 680 & 650 & 700 & 665 & 670 & 650 \\
\hline & 8 & 700 & 760 & 850 & 680 & 650 & 700 & 665 & 670 & 650 \\
\hline
\end{tabular}


Table 15 2004-2011 monthly minimum wage standard (Continued)

\begin{tabular}{|c|c|c|c|c|c|c|c|c|c|c|}
\hline & 9 & 700 & 760 & 850 & 680 & 650 & 700 & 665 & 670 & 650 \\
\hline & 10 & 700 & 760 & 850 & 680 & 650 & 700 & 665 & 670 & 650 \\
\hline & 11 & 700 & 760 & 850 & 680 & 650 & 700 & 665 & 670 & 650 \\
\hline & 12 & 700 & 760 & 850 & 680 & 650 & 700 & 665 & 670 & 650 \\
\hline \multirow[t]{12}{*}{2010} & 1 & 700 & 760 & 850 & 680 & 650 & 700 & 665 & 670 & 650 \\
\hline & 2 & 700 & 760 & 960 & 680 & 650 & 700 & 665 & 670 & 650 \\
\hline & 3 & 700 & 760 & 960 & 680 & 650 & 700 & 665 & 670 & 650 \\
\hline & 4 & 700 & 760 & 960 & 680 & 650 & 700 & 665 & 670 & 650 \\
\hline & 5 & 700 & 920 & 960 & 680 & 650 & 900 & 665 & 670 & 650 \\
\hline & 6 & 700 & 920 & 960 & 680 & 650 & 900 & 665 & 670 & 650 \\
\hline & 7 & 900 & 920 & 960 & 880 & 800 & 900 & 850 & 670 & 650 \\
\hline & 8 & 900 & 920 & 960 & 880 & 800 & 900 & 850 & 670 & 650 \\
\hline & 9 & 900 & 920 & 960 & 880 & 800 & 900 & 850 & 820 & 830 \\
\hline & 10 & 900 & 920 & 960 & 880 & 800 & 900 & 850 & 820 & 830 \\
\hline & 11 & 900 & 920 & 960 & 880 & 800 & 900 & 850 & 820 & 830 \\
\hline & 12 & 900 & 920 & 960 & 880 & 800 & 900 & 850 & 820 & 830 \\
\hline \multirow[t]{12}{*}{2011} & 1 & 900 & 920 & 960 & 880 & 800 & 900 & 850 & 820 & 830 \\
\hline & 2 & 900 & 920 & 1140 & 880 & 800 & 900 & 850 & 820 & 830 \\
\hline & 3 & 900 & 1100 & 1140 & 880 & 800 & 900 & 850 & 820 & 830 \\
\hline & 4 & 900 & 1100 & 1140 & 880 & 800 & 900 & 850 & 820 & 830 \\
\hline & 5 & 900 & 1100 & 1140 & 880 & 800 & 900 & 850 & 820 & 830 \\
\hline & 6 & 900 & 1100 & 1140 & 880 & 800 & 900 & 850 & 820 & 830 \\
\hline & 7 & 1100 & 1100 & 1140 & 880 & 800 & 900 & 1020 & 820 & 830 \\
\hline & 8 & 1100 & 1100 & 1140 & 880 & 800 & 900 & 1020 & 820 & 930 \\
\hline & 9 & 1100 & 1100 & 1140 & 880 & 800 & 900 & 1020 & 820 & 930 \\
\hline & 10 & 1100 & 1100 & 1140 & 880 & 1080 & 900 & 1020 & 820 & 930 \\
\hline & 11 & 1100 & 1100 & 1140 & 880 & 1080 & 900 & 1020 & 820 & 930 \\
\hline & 12 & 1100 & 1100 & 1140 & 880 & 1080 & 1100 & 1020 & 820 & 930 \\
\hline
\end{tabular}

Table 16 2004-2011 weighted monthly minimum wage standard

\begin{tabular}{|c|c|c|c|c|c|c|c|c|c|}
\hline \multirow[t]{2}{*}{ Year } & \multicolumn{3}{|l|}{ Eastern } & \multicolumn{4}{|l|}{ Central } & \multicolumn{2}{|l|}{ Western } \\
\hline & Liaoning & Shandong & Jiangsu & Heilongjiang & Henan & Hubei & Hunan & Guangxi & Guizhou \\
\hline 2004 & 375 & 410 & 580 & 390 & 380 & 400 & 430 & 370 & 363 \\
\hline 2005 & 450 & 530 & 632 & 390 & 405 & 450 & 470 & 460 & 400 \\
\hline 2006 & 532 & 550 & 705 & 543 & 480 & 460 & 540 & 473 & 438 \\
\hline 2007 & 590 & 610 & 775 & 620 & 523 & 560 & 618 & 513 & 567 \\
\hline 2008 & 700 & 760 & 850 & 680 & 650 & 630 & 650 & 618 & 650 \\
\hline 2009 & 700 & 760 & 850 & 680 & 650 & 700 & 665 & 670 & 650 \\
\hline 2010 & 800 & 867 & 951 & 780 & 725 & 833 & 758 & 720 & 710 \\
\hline 2011 & 1000 & 1070 & 1125 & 880 & 870 & 917 & 935 & 820 & 872 \\
\hline
\end{tabular}


$\underline{\text { Table } 17 \text { Macro economic variables }}$

\begin{tabular}{|c|c|c|c|c|c|c|c|c|c|c|}
\hline \multirow[t]{2}{*}{ variables } & \multirow[t]{2}{*}{ Year } & \multicolumn{3}{|l|}{ Eastern } & \multicolumn{4}{|l|}{ Central } & \multicolumn{2}{|l|}{ Western } \\
\hline & & Liaoning & Shandong & Jiangsu & Heilongjiang & Henan & Hubei & Hunan & Guangxi & Guizhou \\
\hline \multirow[t]{8}{*}{ GDP per capita (RMB yuan) } & 2004 & 14258.9 & 10635.4 & 16708.2 & 13236.3 & 7104.3 & 8368.4 & 6993.8 & 5631.3 & 3685.6 \\
\hline & 2005 & 15821.7 & 12445.9 & 20620.0 & 16874.4 & 8802.9 & 9886.3 & 8423.3 & 7022.9 & 4297.6 \\
\hline & 2006 & 19064.9 & 14433.8 & 24510.7 & 20022.7 & 11287.2 & 11541.5 & 10427.0 & 8746.8 & 5376.5 \\
\hline & 2007 & 21785.3 & 16261.6 & 28398.8 & 23716.2 & 13304.9 & 13380.5 & 12123.5 & 10233.1 & 6338.7 \\
\hline & 2008 & 31676.9 & 21736.9 & 39914.9 & 32848.3 & 19109.7 & 19837.0 & 18111.3 & 14578.5 & 9904.2 \\
\hline & 2009 & 35043.7 & 22443.8 & 44119.5 & 35793.7 & 20533.8 & 22659.3 & 20386.7 & 15978.5 & 11062.1 \\
\hline & 2010 & 42188.0 & 27050.9 & 52643.9 & 40853.1 & 24553.3 & 27876.4 & 24410.9 & 20758.9 & 13228.4 \\
\hline & 2011 & 50711.2 & 32816.9 & 62172.8 & 47070.5 & 28686.7 & 34095.6 & 29820.4 & 25233.3 & 16436.6 \\
\hline \multirow[t]{8}{*}{ Agricultural product in GDP (\%) } & 2004 & 12.00 & 11.80 & 9.12 & 12.50 & 19.30 & 18.10 & 18.10 & 23.82 & 21.00 \\
\hline & 2005 & 11.00 & 10.70 & 8.00 & 12.42 & 17.90 & 16.60 & 16.70 & 22.90 & 18.60 \\
\hline & 2006 & 10.60 & 9.80 & 7.20 & 12.10 & 15.50 & 15.20 & 16.50 & 21.80 & 17.30 \\
\hline & 2007 & 10.20 & 9.70 & 7.10 & 13.00 & 14.80 & 14.80 & 17.20 & 21.50 & 16.30 \\
\hline & 2008 & 9.70 & 9.70 & 6.93 & 13.11 & 14.80 & 15.71 & 16.40 & 20.71 & 16.44 \\
\hline & 2009 & 9.40 & 9.50 & 6.60 & 13.40 & 14.30 & 14.00 & 15.20 & 18.90 & 14.20 \\
\hline & 2010 & 8.90 & 9.20 & 6.20 & 12.70 & 14.20 & 13.60 & 14.70 & 17.60 & 13.70 \\
\hline & 2011 & 8.70 & 8.80 & 6.30 & 13.60 & 13.00 & 13.10 & 14.10 & 17.50 & 12.70 \\
\hline \multirow[t]{5}{*}{ Employed population (10 thousand persons) } & 2004 & 4217 & 9180 & 7523 & 3817 & 9717 & 5698 & 6698 & 4889 & 3904 \\
\hline & 2005 & 4221 & 9248 & 7588 & 3820 & 9380 & 5710 & 6326 & 4660 & 3730 \\
\hline & 2006 & 4271 & 9309 & 7656 & 3823 & 9392 & 5693 & 6342 & 4719 & 3690 \\
\hline & 2007 & 4298 & 9367 & 7723 & 3824 & 9360 & 5699 & 6355 & 4768 & 3632 \\
\hline & 2008 & 4315 & 9417 & 7762 & 3825 & 9429 & 5711 & 6380 & 4816 & 3596 \\
\hline
\end{tabular}


Table 17 Macro economic variables (Continued)

\begin{tabular}{|c|c|c|c|c|c|c|c|c|c|}
\hline 2009 & 4341 & 9470 & 7810 & 3826 & 9487 & 5720 & 6406 & 4856 & 3537 \\
\hline 2010 & 4375 & 9588 & 7869 & 3833 & 9405 & 5728 & 6570 & 4610 & 3479 \\
\hline 2011 & 4383 & 9637 & 7899 & 3834 & 9388 & 5758 & 6596 & 4645 & 3469 \\
\hline
\end{tabular}




\section{Competing interest}

The IZA Journal of Labor and Development is committed to the IZA Guiding Principles of Research Integrity. The authors declare that they have observed these principles.

\section{Acknowledgements}

This project is supported by the funds for Project 71173228 from the National Natural Science Foundation of China, and by International Development Research Center of Canada.

Responsible editors: Haroon Bhorat, Ravi Kanbur and Li Shi

\section{Received: 15 March 2015 Accepted: 5 November 2015}

\section{Published online: 27 November 2015}

\section{References}

Card D, Krueger AB (1994) Minimum Wages and Employment: A Case Study of the Fast-Food Industry in New Jersey and Pennsylvania, the American Economic Review 84(4):772-793

Chen J, Shao X, Murtaza G, Zhao Z (2014) Factors that influence female labor force supply in China. Econ Model 37:485-491

Chyi H, Zhou B (2014) The effects of tuition reforms on school enrollment in rural China. Econ Educ Rev 38:104-123

Couch K, Wittenburg D (2001) The response of hours of work to increases in the minimum wage. South Econ J 68(1):171-77

Du Y, Pan W (2009) Minimum wage regulation in China and its applications to migrant workers in the urban labor market. China World Econ 17(2):79-93

Fang T, Lin C (2013) Minimum wages and employment in China. IZA working paper No. 7813

Flinn CJ (2006) Minimum wage effects on labor market outcomes under search, matching, and endogenous contact Rates. Econometrica 74(4):1013-1062

Grossman JB (1983) The impact of the minimum wage on other wages. J Hum Resour 18(3):359-378

Han Z, Wei Z (2006) The empirical research on China's minimum wage standard. Statistical Research 1:35-38 (in Chinese)

Jia P (2014) Employment and working hour effects of minimum wage increase: evidence from China. China World Econ 22:61-80

Linneman P (1982) The economic impacts of minimum wage laws: a new look at an old question. J Polit Econ 90(3):443-69

Luo X (2007) An analysis on the minimum wage's employment effect over the rural-workers in China. J Financ Econ 11:114-123+143 (in Chinese)

Luo X, Cong S (2009) Impact of Chinese minimum wage on other wages based on the effect of catching up with wage. Statistical Research 6:60-65 (in Chinese)

Ma S, Zhang Z, Zhu X (2012) The effect of minimum wage on average wage and employment. Economic Research, 5:132-146 (in Chinese)

Machin S, Manning A, Rahman L (2003) Where the minimum wage bites hard: introduction of minimum wages to a low wage sector. J Eur Econ Assoc 1(1):154-180

Maynerisy F, Poncet S, Zhang T (2014) The cleansing effect of minimum wage Minimum wage rules, firm dynamics and aggregate productivity in China. working paper available at https://www.wto.org/english/res_e/reser_e/gtdw_ e/wkshop14_e/florian_mayneris_e.pdf

Neumark D (2001) The employment effects of minimum wages: evidence from a prespecified research design the employment effects of minimum wages. Ind Relat 40(1):121-144

Neumark D, Schweitzer M, Wascher W (2004) Minimum wage effects throughout the wage distribution. J Hum Resour 204(2):425-450

Rama M (2001) The consequences of doubling the minimum wage: the case of Indonesia. Ind Labor Relat Rev 54(4):864-81

Stewart MB, Swaffield JK (2008) The other margin: do minimum wages cause working hours adjustments for low-wage workers? Economica 75(297):148-167

Stewart MB (2012) Wage inequality, minimum wage effects, and spillovers. Oxford Economic Papers, 64(4): 616-634

Stigler GJ (1946) The economics of minimum wage legislation. Am Econ Rev 36(3):358-365

Tong D (2006) Does minimum wage standard reduces competition? Xinhua Net, available at: http://news.xinhuanet. com/comments/2006-05/10/content_4527876.htm

Wang X (2012) When workers do not know -the behavioral effects of minimum wage laws revisited. J Econ Psychol 33:951-962

Wang J, Gunderson M (2011) Minimum wage impacts in China: estimates from a prespecified research design, 2000-2007. Contemp Econ Policy 29(3):392-406

Wang J, Gunderson M (2012) Minimum wage effects on employment and wages: dif-in-dif estimates from Eastern China. Int J Manpow 33(8):860-876

Ward PS (2014) Measuring the level and inequality of wealth: an application to China. Rev Income Wealth 60(4):613-35

Wu X, Perloff JM (2005) China's income distribution, 1985-2001. Rev Econ Stat 87(4):763-775

Xiao $X-Y$, Xiang B-L (2009) The impact of minimum wage policy on wages and employment in China. Information Management, Innovation Management and Industrial Engineering, International Conference on. Vol. 2. IEEE

Yang J, Gunderson M (2013) The Impact of minimum wages on migrant workers' wages, Beijing Normal University Working paper

Zhang W (2004) The curse of minimum wage. Southern Weekly, available at: http://view.news.qq.com/a/20070422/ 000006.htm 